$\begin{array}{ll} & \text { Etnográfica } \\ \text { etnográfica } & \text { Revista do Centro em Rede de Investigação em }\end{array}$

Antropologia

vol. 17 (1) | 2013

Vol. $17(1)$

\title{
Estudar o turismo hoje: para uma revisão crítica dos estudos de turismo
}

Studying tourism today: towards a critical review of tourism studies

\section{Sofia Sampaio}

\section{(2) OpenEdition}

\section{Journals}

\section{Edição electrónica}

URL: https://journals.openedition.org/etnografica/2615

DOI: 10.4000/etnografica.2615

ISSN: 2182-2891

\section{Editora}

Centro em Rede de Investigação em Antropologia

\section{Edição impressa}

Data de publição: 1 fevereiro 2013

Paginação: 167-182

ISSN: 0873-6561

\section{Refêrencia eletrónica}

Sofia Sampaio, «Estudar o turismo hoje: para uma revisão crítica dos estudos de turismo», Etnográfica [Online], vol. 17 (1) | 2013, posto online no dia 13 março 2013, consultado o 10 fevereiro 2022. URL: http://journals.openedition.org/etnografica/2615 ; DOl: https://doi.org/10.4000/etnografica.2615

\section{(c) (i) (8)}

Etnográfica is licensed under a Creative Commons Attribution-NonCommercial 4.0 International License. 


\section{Estudar o turismo hoje: para uma revisão crítica dos estudos de turismo}

\section{Sofia Sampaio}

Aproveitando a publicação, em 2009, de The Sage Handbook of Tourism Studies e de The Sociology of Tourism: European Origins and Developments - duas extensas antologias sobre o estudo do turismo nas ciências sociais -, o artigo discute as tradições académicas que cada um destes volumes representa e defende, nomeadamente, uma tradição anglófona transatlântica e uma tradição europeia continental. Identificam-se algumas tendências dominantes para, no final, se propor a "rematerialização" dos estudos de turismo partindo de um ponto de vista local, focado nas práticas e sensível às assimetrias visíveis (ou não) no terreno.

PALAVRAS-CHAVE: estudos de turismo, revisão crítica, tradição anglófona, tradição europeia.

Studying tourism today: towards a critical review of tourism studies - The article takes the publication, in 2009, of The Sage Handbook of Tourism Studies and The Sociology of Tourism: European Origins and Developments - two anthologies that review how tourism has been studied in the social sciences - as an opportunity to discuss the traditions represented and defended in each of these books, namely: a transatlantic Anglophone tradition, and a European continental one. Some of the main tendencies are identified, so as to propose, in the end, the "rematerialization" of tourism studies through the adoption of a local point of view that focuses on the practices, but is also sensitive to the asymmetries that are visible (or not) from the ground.

KEYWORDS: tourism studies, critical review, Anglophone tradition, European tradition.

SAMPAIO, Sofia (psrss@iscte.pt) - Centro em Rede de Investigação em Antropologia, ISCTE - Instituto Universitário de Lisboa, Portugal. 
O ESTUDO DO TURISMO, UM INTERESSE DE INVESTIGAÇÃO QUE SE foi desenvolvendo nas margens das ciências sociais - quer nas notas de antropólogos que registavam, frequentemente com desagrado, a presença de turistas no "seu" campo (Smith 1978: 1), quer nas reflexões dos sociólogos do trabalho, confrontados com o papel crescente do lazer nas sociedades modernas - parece finalmente ter encontrado reconhecimento académico. Tendo-se tornado, sobretudo a partir da segunda metade do século XX, uma prática social alargada, o turismo figura hoje como tema de um vasto número de conferências e publicações especializadas, ancoradas nas mais diversas perspetivas.

É neste contexto de franca expansão que surgem The Sage Handbook of Tourism Studies (Jamal e Robinson 2009) e The Sociology of Tourism: European Origins and Developments (Dann e Parrinello 2009), cuja publicação quase em simultâneo faz deste um momento oportuno para uma revisão crítica da área. Os dois volumes oferecem um balanço do que tem sido feito, permitindo-nos apreciar como é que o turismo se tem vindo a constituir - construir e desconstruir como um objeto de estudo. No entanto, a forma como este objetivo é concretizado é bastante diferente: se o manual da Sage representa, e de certa forma consagra, a forte presença anglo-americana na área, uma presença que valoriza a pluridisciplinaridade e que revela preocupação em sinalizar e abraçar novas tendências, já Sociology of Tourism se constrói deliberadamente em oposição a esta presença (que considera hegemónica) para, por um lado, dar prioridade a perspetivas europeias e continentais e, por outro, recuperar um passado que vem reafirmar a centralidade da sociologia nos estudos de turismo. Ao oferecer uma visão geral das principais questões e controvérsias que dominam o campo, a leitura conjunta destes dois volumes parece-me vantajosa, podendo contribuir para uma melhor compreensão do tipo de estudos de turismo que se faz (ou se quer fazer) em Portugal, nomeadamente no âmbito da antropologia.

\section{UM GUIA DEFINITIVO? THE SAGE HANDBOOK OF TOURISM STUDIES}

Das duas publicações em revista, esta é, sem dúvida, a mais ambiciosa: com mais de setecentas páginas e um total de trinta e nove capítulos, The Sage Handbook of Tourism Studies pretende constituir-se como uma "base de conhecimento" sobre o estudo do turismo. O livro divide-se em três partes: "Approaches to tourism studies", que apresenta as principais abordagens que têm surgido nas diferentes áreas disciplinares (antropologia, sociologia, estudos culturais, estudos de desenvolvimento, história, geografia, economia, ciência política, estudos urbanos, entre outras); "Key topics in tourism", que faz o estado da arte do campo a partir de alguns tópicos principais (que vão desde a relação do turismo com a religião e a espiritualidade ao turismo voluntário, turismo rural, gestão e marketing de destinos turísticos, prevenção e segurança no turismo, etc.); "Critical issues and emerging perspectives", que discute as problemáticas 
mais importantes e as tendências emergentes (tais como festivais e eventos, turismo e pós-colonialismo, turismo e performance, turismo e ética). Sendo os capítulos escritos por especialistas, os organizadores não hesitam em apresentar este manual como um "guia definitivo, crítico e indispensável" para académicos de diversas disciplinas (Jamal e Robinson 2009: xvii).

E é, de facto, grande o número de tópicos e autores que se reúnem nesta obra. No entanto, apesar da diversidade temática e metodológica, bem como da pluralidade de vozes, é possível discernir uma certa convergência de tendências, nomeadamente: (1) tendência culturalista; (2) tendência inter ou mesmo transdisciplinar; (3) tendência para privilegiar a ótica do consumidor, em detrimento das questões de produção/trabalho; (4) tendência para sobrevalorizar perspetivas microscópicas (centradas, por exemplo, no corpo), sob o risco de perder de vista outras escalas e relações; por fim, ainda que vários autores refiram a importância de se demarcarem de abordagens economicistas, é notório (5) um compromisso com o setor empresarial turístico. Isto é, ainda que se verifiquem diferenças claras no tipo de análise e de enfoque entre os contributos provenientes das ciências sociais e humanidades e os contributos provenientes da economia e gestão, sente-se, por outro lado, uma certa preocupação com a "aplicabilidade" da investigação dos primeiros aos segundos - uma tendência que poderá refletir a crescente dependência das universidades e dos centros de investigação de financiamentos privados (nomeadamente, oriundos do setor turístico e de serviços de consultadoria).

Em relação ao primeiro aspeto (tendência culturalista), não constitui uma surpresa. Grande parte da literatura sobre turismo que nos chega dos Estados Unidos, Canadá e Reino Unido - esta antologia define-se geograficamente como cross-Atlantic (2009: xvii) - apresenta um forte pendor culturalista. $\mathrm{Na}$ verdade, o manual da Sage vem consagrar uma agenda de investigação do turismo que se tem vindo a formar no mundo anglo-saxónico sob a égide dos estudos culturais (uma aproximação que o termo tourism studies consegue veicular), ou, de uma forma mais geral, sobre o chamado cultural turn nas ciências sociais, assente na rejeição de abordagens quer positivistas quer economicistas do turismo, como resposta à condição de intensa "culturalização" das sociedades contemporâneas ditas pós-modernas (cf. Rojek e Urry 1997). ${ }^{1}$

1 O estudo do turismo nestes moldes não pode ser separado do esforço de profunda reconceptualização que a sociologia anglo-americana desenvolveu nos últimos 25 anos (em que participaram nomes como Chris Rojek, Scott Lash e John Urry), a fim de dar conta das mudanças que terão transformado as sociedades industriais em sociedades pós-industriais, anunciando o fim do "capitalismo organizado" e o início da "era da informação", da modernidade reflexiva (ou "pós-modernidade"), com a consequente valorização do lazer, do consumo, da mobilidade. Não é por acaso que a implosão ou "desdiferenciação" entre categorias sociais e culturais tradicionais é invocada na abertura do Sage Handbook como um marco das novas tendências aqui defendidas (Jamal e Robinson 2009: 3-4). 
A presença dos estudos culturais neste volume é notória: para além de terem direito a um capítulo próprio, assinado por David Crouch, os estudos culturais são discutidos, por exemplo, no capítulo sobre a relação entre turismo e desenvolvimento (Jamal e Robinson 2009: 147, 159). O turismo é tratado sobretudo como um fenómeno cultural ("an intrinsically cultural phenomenon", 2009: 3,7 ), um espaço mobilizador de encontros entre diversas expressões culturais tangíveis e intangíveis, gerador de significados que se supõem (direta ou indiretamente) ligados à modernidade (e, nalguns casos, à sua mais recente atualização terminológica, a "globalização"). A base multidisciplinar desta antologia é também comum aos estudos culturais. Mais do que interdisciplinaridade, o que se defende aqui é uma espécie de desenraizamento e deslocamento disciplinar, uma "transdisciplinaridade" (2009: xvii, 2), que pretende questionar as fronteiras não apenas entre disciplinas tradicionais, mas também entre outros "compartimentos" conceptuais, tais como "lazer" (ligado à sociologia do trabalho), "hospitalidade" (ligado à gestão) e turismo (2009: 30), áreas nas quais vários dos contributos aqui reunidos têm origem.

Em 1997, Chris Rojek e John Urry - sociólogos britânicos associados aos estudos culturais ${ }^{2}$ - propunham a "desconstrução" do termo "turismo", que deixaria de ser visto como um fenómeno social claramente circunscrito e identificável, para passar a ser um conjunto complexo de discursos e práticas sociais (Rojek e Urry 1997: 1; cf. Franklin e Crang 2001: 7). Esta abordagem, apesar de não ser a única (o geógrafo Sanjay K. Nepal avança uma definição mais positivista de turismo; cf. Jamal e Robinson 2009: 130), tem forte representatividade nesta antologia, onde a questão da definição do objeto de estudo é constantemente adiada, ou mesmo rejeitada. Para Naomi Leite e Nelson Graburn, por exemplo, o que caracteriza as intervenções antropológicas no âmbito dos estudos de turismo não é tanto o objeto de estudo (comum às outras ciências sociais), como a combinação metodológica de uma abordagem holística com pesquisas etnográficas (2009: 36). O turismo é entendido como um fenómeno cultural complexo que resiste a ser definido, justificando a rejeição de modelos e tipologias, a favor de estudos locais, concretos e particulares, que privilegiam a pluralidade de práticas, a partir das quais se procura explorar ambiguidades, contingências e "deslizes" (slippages) de significação (2009: 37).

A necessidade de valorizar o concreto e o particular é partilhada por autores de outras ciências sociais. Na sociologia, Adrian Franklin lamenta todo um período em que o turismo foi predominantemente estudado a partir de teorizações abstratas, assentes, em larga medida, numa série de "dualismos" "everyday : extraordinary; home : away; profane : sacred; inauthentic : authentic" - em vez de ser estudado "through reconstructing precise historical and 
cultural accounts of its emergence and operation" (2009: 73). O historiador John K. Walton expressa uma preocupação semelhante, sublinhando a necessidade de se prestar mais atenção ao contexto e ao pormenor histórico, o que permitirá refutar noções simplistas, mas vastamente difundidas, sobre o turismo, nomeadamente a noção de "turismo de massas", a ideia de que o turismo teve origem num único fenómeno (o Grand Tour), ou, de uma forma mais geral, a ideia de que existe uniformidade nas experiências turísticas, em detrimento de especificidades espaciais e temporais (2009: 117).

De facto, uma tendência comum a todos os capítulos (à exceção do capítulo 10, sobre a economia do turismo internacional) é a identificação dos autores, de uma forma mais ou menos assumida, com uma narrativa de rutura em relação a estudos e abordagens anteriores - um gesto frequentemente acompanhado por um apelo ao "novo" (por exemplo, 2009: 685). Apesar de algumas diferenças, há um padrão que emerge: para trás ficam os "estudos de impacte" (característicos da antropologia e da geografia; 2009: 40, 133), a preocupação com fenómenos de "aculturação" (agora preterida pelo "hibridismo"; 2009 : 40), e a elaboração (sobretudo na sociologia) de modelos teóricos explicativos, tais como o resort cycle model e o tourist gaze (2009: 75). No capítulo escrito por Adrian Franklin, fala-se de uma "nova vaga" na sociologia do turismo, de um critical turn que procura romper com vários conceitos e abordagens da primeira vaga (protagonizada pelos sociólogos Dean MacCannell e John Urry), e adotar uma visão mais "generosa e aberta" do turismo (2009: 73). Os temas que este sociólogo identifica são mais ou menos transversais a todos os capítulos do livro: reconfiguração do turismo como uma prática quotidiana, vulgar e geograficamente difundida; rejeição da primazia da visão (ou "ocularcentrismo") e do cognitivo, típicos dos estudos anteriores, a favor de uma maior atenção ao corpo, aos sentidos, à sexualidade e à performance (2009: 73-75). A nova fase é louvada pela sua sofisticação (2009: 40), que procura dar conta da diversidade e agencialidade dos atores sociais, resultando numa literatura rica em nuances (cf. 2009: 41).

O contributo dos estudos culturais (ou de uma das suas correntes mais fortes) é, também aqui, evidente, já que o que se pretende valorizar - na linha de MacCannell (1999 [1976]), como David Crouch refere (em Jamal e Robinson 2009: 90) - são as práticas do turista e não tanto as indústrias e instituições promotoras do turismo. Estas práticas são agora concebidas como embodied practices, numa correção a tendências teóricas anteriores que privilegiavam as representações e enfatizavam os processos de mediação (2009: 90). Por outras palavras, conceitos como mediação e representação (curiosamente, na base das origens e do sucesso dos estudos culturais) perdem relevância. O corpo impõe-se cada vez mais como o único mediador legítimo entre o turista/consumidor (agora reformulado como ativo, reflexivo, "coprodutor"; 2009: 91) e a experiência turística, o que também vem justificar a crescente importância do 
conceito de performance (2009: 89). O preço a pagar por esta valorização da performance é o contexto: passa-se de uma semiótica determinada pelo contexto (context-driven) para uma semiótica "encarnada" ou "corporizada" (uma embodied semiotics; 2009: 93), que parece prescindir de mediadores, contextos ou qualquer tipo de exterioridade (incluindo o público que, enquanto produtor ativo de significados, passa a ser visto como parte integrante da performance).

Este embodied turn (2009: 640) teve especial expressão nos estudos de género (cf. capítulo 35), que rejeitaram a neutralidade tácita do "olhar turístico", reclamando a sua ligação ao corpo, ao género, à sexualidade e aos outros sentidos (cf. Veijola e Jokinen 1994). Um outro contributo importante foi a teorização de formas de poder e agencialidade negociadas e vivenciadas horizontalmente, ou até de baixo para cima. No entanto, é difícil ignorar a ligação entre estes desenvolvimentos teóricos e desenvolvimentos históricos concomitantes - nomeadamente, a expansão e consolidação das práticas turísticas dentro de um modelo de sociedade capitalista. $\mathrm{O}$ apelo aos vários sentidos tem marcado a própria indústria, forçada a reinventar-se face à pressão concorrencial que decorre do seu próprio sucesso global, nomeadamente através da criação de novos "produtos", como o turismo enológico, gastronómico, de aventura, rural, o ecoturismo e o agroturismo. ${ }^{3}$ Como destrinçar as novas agencialidades ("performativas" e "corporizadas") da esfera de influência da chamada experience economy (Löfgren 2008), que coloca o corpo humano no centro da produção de serviços e mercadorias, é um problema que continua por resolver.

Uma última tendência presente neste livro é a valorização da ética, ou ethical turn (Jamal e Robinson 2009: 615), cuja matriz filosófica assenta no liberalismo, utilitarismo e individualismo de Stuart Mill e Locke, bem como na ética do "outro" e do respeito pela diferença de Levinas. Na prática, esta ética aplicada ao turismo traduz-se numa ética conservacionista ou "ambiental" (2009: 210) e numa ética de responsabilidade social das empresas, que passa, por exemplo, pela democratização do acesso ao turismo (2009: 373, 383) e o envolvimento das comunidades locais nos processos de decisão (2009: 423). A discussão destes assuntos é, porém, bastante limitada: a ideia de um turismo sustentável, "ético" ou "responsável" - quer se trate de ecoturismo, fair trade ou pro-poor tourism - está inserida numa lógica de consumo, que faz do consumidor-turista o sujeito ético por excelência. Por outras palavras, o "ecoturismo" é indissociável do green consumerism (2009: 212), o que afasta do horizonte ético posições anticonsumistas, ou mesmo anticapitalistas.

Esta visão é confirmada nos capítulos sobre gestão, marketing e planeamento (na parte central do livro). Longe das críticas ao turismo (relegadas para o

3 O bungee jumping, em que o turista é convidado a mergulhar literalmente na paisagem de que antes era espectador, condensa de forma eloquente esta reorientação de perspetivas ocularcêntricas para perspetivas centradas na imersão multissensorial do corpo (cf. Bell e Lyall 2008 [2002]). 
âmbito da academia, ou para o passado), das dúvidas e hesitações, o objetivo do planeamento turístico é claro: "to minimize the adverse effects of tourism development while maximizing the potential benefits" (2009: 418). No final, torna-se evidente que, para que possa ser efetivamente sustentável, o turismo - entendido como uma atividade económica transversal - requer um esforço enorme e contínuo de sustentação, um esforço que depende de equilíbrios frágeis assentes em três pilares - sustentabilidade social, sustentabilidade ambiental e sustentabilidade económica (cf. 2009: 41 l) - que, por sua vez, estão assentes num contexto político favorável (isto é, de estabilidade política e social) capaz de garantir o sucesso dos investimentos e empreendimentos. É sobretudo em relação a estes problemas que o pendor aplicado de muitos dos contributos se faz sentir - por exemplo, no capítulo sobre turismo rural que, depois de diagnosticar o fim de uma "época de ouro", lança uma série de recomendações práticas para contornar as dificuldades que se avizinham (2009: 365-366). Alguns autores chegam mesmo a defender uma agenda de investigação mais "holística", capaz de interligar a literatura empresarial (vocacionada para os resultados) e a literatura das ciências sociais e humanas (focalizada nos processos) (2009: 497), o que parece ir ao encontro dos organizadores, que, na conclusão, defendem a aproximação destes dois tipos de abordagem (2009: 696).

\section{UMA QUESTÃO DE CHAUVINISMO? THE SOCIOLOGY OF TOURISM: EUROPEAN ORIGINS AND DEVELOPMENTS E A ALTERNATIVA EUROPEIA NÃO ANGLÓFONA}

Uma visão muito diferente (apesar de sobreposições e convergências) é-nos dada na segunda publicação em revista, também de 2009, editada por Graham Dann e Giuli Liebman Parrinello, dois sociólogos europeus. Sob a alçada do comité de investigação do turismo internacional (RC50) da Associação Internacional de Sociologia, esta coletânea surge como resposta à hegemonia anglo-saxónica nesta área de estudos (patente, para começar, no monopólio da língua inglesa nas publicações académicas internacionais mais importantes). O objetivo é comparar as teorias sociais do turismo e estabelecer as suas origens europeias, mas também corrigir a profunda "amnésia intelectual" (Dann e Parrinello 2009: 49) que vem caracterizando os "novos" estudos de turismo. A ideia de que esta é uma área de estudos nova, tão cara a alguns autores anglófonos, ${ }^{4}$ é amplamente contrariada nos nove capítulos que discutem o aparecimento e a evolução da sociologia do turismo

4 Valene Smith situou o primeiro artigo de antropologia do turismo em 1968 (Smith 1978: 1). No entanto, na introdução ao Sage Handbook, os organizadores reconhecem que o estudo do turismo é mais antigo, recuando aos anos 1920 (Jamal e Robinson 2009: 1). 
em contextos nacionais específicos, nomeadamente nos países de expressão alemã (Alemanha, Áustria e Suíça), em França, em Itália, na Polónia, na ex-Jugoslávia (com ênfase na Croácia), na Escandinávia (sobretudo Noruega e Suécia), em Espanha, no Benelux (Bélgica e Holanda, o Luxemburgo é excluído) e na Grécia. O que emerge deste retrato geral é que o estudo do turismo na Europa remonta pelo menos à década de 1930, sendo por isso muito anterior ao boom dos estudos de turismo, de base anglófona, que teve lugar nos últimos vinte e cinco anos.

São sete as principais problemáticas (nomeadas e discutidas no capítulo introdutório) que orientaram a elaboração deste volume: (1) a origem e constituição das sociologias nacionais e europeias; (2) a relação entre sociologia geral e sociologia do turismo; (3) a relação entre sociologia do turismo e sociologia do lazer (a primeira associada ao turismo internacional, a segunda às práticas de lazer domésticas); (4) a definição do objeto ("turismo"); (5) a multi e interdisciplinaridade; (6) a questão linguística e, finalmente, (7) a questão ideológica (isto é, as imbricações entre sociologia, turismo e ideologia). Mas o grande objetivo desta antologia - claramente enunciado pelos organizadores e perseguido por alguns dos autores (nomeadamente, o alemão Hasso Spode e o norueguês Jens Jacobsen) - é demonstrar que grande parte das teorias sociológicas sobre o turismo, hoje associadas a autores anglófonos, foi de facto antecipada na Europa continental por autores como Durkheim, Marx, Enzensberger, Simmel, Huizinga, Benjamin, Veblen, Foucault, Eco e Bourdieu (Dann e Parrinello: 42-49).

Os autores da maior parte dos contributos aqui reunidos possuem uma longa carreira na área do turismo, com ligações quer à academia quer à investigação aplicada, quer mesmo à administração pública. Muitos são protagonistas da história que contam - é o caso de Marie-Françoise Lanfant, autora do capítulo francês, que foi a principal impulsionadora, em 1994, do RC50 (uma cisão do Comité de Investigação do Lazer, que Joffré Dumazedier formara em 1953). Por outro lado, são várias as abordagens adotadas nos diversos capítulos, oscilando entre apreciações generalistas e algo impressionistas (como no capítulo polaco), revisões do campo centradas nas publicações (como no caso grego), e contributos mais ambiciosos que não descuram as correntes intelectuais, locais e internacionais nem a respetiva ancoragem institucional e académica (como nos capítulos alemão, francês e italiano), as organizações sociais e civis extra-académicas (como no caso belga e holandês), ou os dois últimos aspetos (como no caso escandinavo). O capítulo espanhol é o menos convencional - e possivelmente também o mais arriscado - ao optar por uma narrativa focada no trabalho de três "pioneiros" situados à margem da academia espanhola, nomeadamente, Mario Gaviria, Francisco Jurdao e José Luís Febas, descritos, respetivamente, como "a professional sociologist", "an accidental anthropologist” e "a semiologist” (Dann e Parrinello 2009: 243). 
Torna-se claro que, para os organizadores (e alguns dos autores), falar de uma sociologia do turismo europeia é, basicamente, falar dos casos alemão e francês, deliberadamente colocados no início do livro (2009: 49). A sociologia do turismo que se desenvolveu na maior parte dos países europeus é, deste modo, vista como derivativa de uma destas tradições (2009: 12). O que as une é, basicamente, o mesmo impulso de transformar o estudo do turismo num ramo da sociologia, e não da economia (2009: 72) - partindo da necessidade de distinguir (como faz Hunziger) entre "the economic aspects of tourism" e "tourism as the object of noneconomic subjects" (2009: 31).

O sucesso deste empreendimento tem sido volátil, tendo-se sucedido, ao longo do século XX, períodos de forte originalidade e teorização, seguidos de outros de estagnação, orientados para uma investigação aplicada às necessidades específicas da indústria. No caso alemão, o autor Hasso Spode considera três períodos particularmente produtivos: as décadas de 1930 e 1940; os anos 1960 (no âmbito do Studienkreis, que promoveu a interdisciplinaridade, ou sob a influência da Escola de Frankfurt); e a década de 1990. Segundo Spode, o período atual corresponderia a uma fase de estagnação (2009: 87). No capítulo francês, Marie-Françoise Lanfant centra-se na discussão da relação entre a sociologia do turismo e a sociologia, que passa pela constituição do turismo como um objeto sociológico. Baseando-se em Marcel Mauss, o contributo de Lanfant foi propor o conceito de turismo como "um fenómeno social total" isto é, um fenómeno eminentemente "social" (e não "the product of individual conscience"), que não pode ser reduzido "to its mere representation in social discourse or to the subjective experiences of actors" (2009: 108-109). A criação de um campo de pesquisa dedicado ao turismo internacional tinha como objetivo, segundo a autora, por um lado, ultrapassar as esferas do local e nacional, integrando-as numa dimensão global (que, nos anos 1990, se tornava cada vez mais evidente) e, por outro, ultrapassar a separação teórica e metodológica entre sociedades emissoras de turistas (as sociedades "desenvolvidas"), objeto da sociologia do lazer, e sociedades recetoras de turistas (as sociedades "em vias de desenvolvimento"), objeto da antropologia e da etnologia (2009: 126).

O envolvimento do turismo em questões ideológicas emerge nos vários capítulos: se na França dos anos 1950 a sociologia do lazer se desenvolveu no seio de uma economia liberal, em pleno clima de Guerra Fria e por reação ao marxismo (2009: 112), o lazer era já uma preocupação mais antiga (remontando pelo menos ao século XIX), que opunha operários a patrões, na questão da redução da jornada de trabalho. Por razões capitalistas (diminuição da produtividade), moralistas (prevenção do alcoolismo e outros vícios), políticas (propagação de ideias revolucionárias) ou mesmo paternalistas (promoção do desenvolvimento pessoal e religioso), o lazer e o tempo livre eram tópicos controversos, carecendo, na opinião de muitos, de algum tipo de controlo (cf. capítulo sobre a Bélgica e a Holanda, 2009: 277-278). Ao longo do século XX, 
o turismo viria a assumir contornos ideológicos renovados: na Itália dos anos 70, os membros filiados na AIEST (associação internacional de cientistas especialistas em turismo) defendiam a investigação do turismo em articulação com a questão do desenvolvimento, entrando em polémica com o que ficou conhecido por "sociologia antropologizada" (2009: 135), apoiada pela UNESCO e o Banco Mundial, que sublinhava os aspetos "degenerativos" do turismo para as comunidades e culturas locais (o que lhes custou a acusação, pelos primeiros, de "imobilismo a-histórico").

Não sendo um tópico ideologicamente neutro (se é que é possível descobrir algum que o seja), o turismo não pode, porém, ser reduzido a um único uso ideológico. Como Dann e Parrinello (2009: 28) referem no capítulo introdutório, o turismo floresceu quer em regimes fascistas (como na Alemanha nazi, no movimento Kraft durch Freude) quer em regimes democráticos (durante a Frente Popular francesa), quer mesmo em regimes socialistas, como se pode constatar no capítulo sobre a ex-Jugoslávia. Esta consciência histórica está, provavelmente, na base da advertência dos organizadores, feita logo na introdução (2009: 24), em relação à permeabilidade ideológica dos estudos aqui apresentados.

No geral, é de louvar, nesta antologia, o objetivo de trazer à luz aspetos da história do turismo e do seu estudo que estavam esquecidos. Os estudos de turismo só têm a ganhar com a preservação, nas palavras de Hasso Spode, de uma "memória cumulativa" (Dann e Parrinello 2009: 88), que lhes conferirá profundidade histórica e maior rigor na avaliação do "novo". É igualmente de louvar a valorização de outras línguas que não o inglês (todas as citações são feitas na língua original e seguidas da tradução inglesa), que, aceitando pragmaticamente o uso do inglês como língua franca, não cede, porém, ao monolinguismo, cada vez mais generalizado, que ameaça separar o meio académico de alguns dos seus interlocutores mais importantes. Por fim, um dos pontos fortes de The Sociology of Tourism é a variedade de perspetivas que emerge dos contextos geográficos e históricos específicos ("nacionais") de cada capítulo. A perspetiva nacional comporta riscos evidentes, como o de se trocar um tipo de etnocentrismo (anglófono) por outro (germanófono e francófono), considerado "correto" (2009: 11 ). ${ }^{5}$ No entanto, o recurso ao nacional como instrumento de investigação é, de certo modo, inevitável - sobretudo quando se trata de comparar tradições académicas que, pelo menos nos últimos cem anos, se constituíram num quadro marcadamente nacional.

5 O risco de essencialismo também emerge de vez em quando, por exemplo no capítulo polaco, em que se fala da resistência à viagem e da celebração da imobilidade como características da cultura polaca (Dann e Parrinello 2009: 182), ou quando se refere, num quadro de abstrações dicotómicas meramente especulativas (e politicamente perigosas), que os judeus tipificam a rejeição simultânea de "casa" e "mundo" e o eterno anseio por uma terra prometida (2009: 184). 
Um problema mais evidente, e de difícil resolução, é a questão da representatividade destas "histórias" nacionais: os organizadores consideram os contributos aqui apresentados como representativos da investigação sobre turismo que se faz na Europa, descrevendo os autores selecionados como "the leading representatives for their respective countries and regions" (2009: 62). Mas a opção editorial de incluir uns autores e não outros - já para não falar da opção de não incluir alguns países - é suscetível de questionamento. O silêncio sobre a influência soviética nos estudos do turismo dos países do bloco socialista poderá ser um efeito deste tipo de escolha. Para além disso, a não inclusão de países como Portugal e a Rússia - aparentemente, por apresentarem um número reduzido de centros de investigação nesta área (2009: 62, nota 1) - pode reavivar argumentos linguísticos (agora imputáveis a francófonos e germanófonos) ou até ideológicos, ainda que, mais provavelmente, seja o resultado de redes de conhecimento, através das quais os centros e as margens da academia ganham forma.

Apesar de partilhar muitos dos postulados dos estudos de turismo anglófonos (com os quais, de resto, mantém um diálogo próximo), o livro da Emerald é mais prudente em relação aos ganhos dos últimos anos. Em alguns pontos, as diferenças são mais de grau do que de género: a interdisciplinaridade, por exemplo, é defendida, mas sem que o enquadramento disciplinar seja completamente posto em causa (firmemente ancorada na sociologia, esta antologia demonstra que o estudo do turismo há muito que se faz numa base interdisciplinar); a produção de definições (provisórias) continua a ser um objetivo. Segundo Hasso Spode, ainda que partilhando o mesmo vocabulário ("construção", "distinção", "liminalidade", "gaze" - Spode é particularmente crítico do último, associado ao sociólogo inglês John Urry), os estudos de turismo dos países de expressão alemã e da Europa continental são, em geral, menos dados a um pensamento pós-moderno (2009: 87-88), e mais inclinados para resgatar o turismo de perspetivas a-históricas ou trans-históricas (ainda que estas tendências não se confirmem em todos os capítulos deste livro). ${ }^{6}$ Ao contrário do que sucede no manual da Sage, a subordinação do estudo do turismo à investigação aplicada é motivo de grande preocupação para os organizadores e alguns dos autores de The Sociology of Tourism, nomeadamente por implicar a rejeição de questões polémicas a favor da resolução pragmática de problemas

6 A atração por teorizações mais abstratas - que tratam o turista como uma categoria existencial e o turismo como uma metáfora da "condição pós-moderna"- não deixam de transparecer nestes contributos, nomeadamente nos capítulos italiano (por exemplo, Dann e Parrinello 2009: 161) e polaco. Também no capítulo sobre a Grécia, os autores (um sociólogo e uma antropóloga) dão conta da crescente influência do pós-estruturalismo, sobretudo nos estudos de pendor antropológico (2009: 301 ). O trabalho de Galani-Moutafi, antropóloga e coautora deste capítulo, sobre identidade e alteridade (Galani-Moutafi 2000) é, de resto, ilustrativo de muitas das tendências criticadas por Spode. 
“concretos" (Dann e Parrinello 2009: 124). ${ }^{7}$ Mas não há dúvida de que o grande mérito do livro da Emerald reside na variedade de tradições que nos apresenta, que nos permite colocar em perspetiva as tendências dominantes dos estudos do turismo anglófonos. Há alguns desequilíbrios entre os capítulos, cujo sucesso, em última análise, depende da forma como cada autor conseguiu captar o dinamismo e a especificidade dos processos históricos, de forma a equilibrar o cariz generalista e sistematizador que orienta a obra (sobretudo em torno das categorias "nacional" e "europeu").

\section{CONCLUSÃO: PARA ONDE?}

Como é possível constatar pela leitura destes dois volumes, o processo de constituição do turismo como objeto de investigação nas ciências sociais - seja no mundo anglófono, seja na Europa continental - passou, em boa medida, pela emancipação de perspetivas predominantemente económicas. Os estudos culturais deram um importante contributo na prossecução deste objetivo, nomeadamente ao sublinharem o papel da linguagem, dos processos simbólicos e das representações na constituição de objetos, lugares, experiências e sujeitos turísticos, mas também ao insistirem na polissemia e polivocalidade de todas as práticas sociais, incluindo as turísticas. O resultado, como o manual da Sage ilustra, foi a generalização das metodologias interpretativas e o alargamento explosivo do âmbito da investigação, que passou a levar em conta processos culturais antes ignorados - relacionados, por exemplo, com etnicidade, autenticidade, identidade, género e sexualidade (Jamal e Robinson 2009: 39-40) - e a incorporar pontos de vista alternativos que propõem ou recuperam narrativas contra-hegemónicas (veja-se o capítulo sobre turismo e pós-colonialismo, 2009: 514-515).

Mas se os novos rumos tornaram este campo de estudo mais variado, mais interessante, ou até mais divertido (Franklin e Crang 2001: 14), está por provar se o tornaram menos repetitivo e mais crítico. ${ }^{8}$ Com efeito, do mesmo modo que não faz sentido reduzir o turismo a uma atividade de cariz estritamente económico, também não faz sentido alienar as práticas turísticas dos contextos materiais (sociais, económicos e político-económicos) em que se inserem. Esta preocupação esteve na base dos estudos culturais, atingindo a

7 As questões ideológicas têm menor expressão no manual da Sage. No entanto, veja-se o capítulo 33, de R. E. Wood, que se debruça sobre turismo, política internacional e neoliberalismo, bem como o capítulo 11, de Linda K. Ritcher, sobre turismo e ciência política.

8 Veja-se, a este respeito, a crítica de Raoul Bianchi (2009). O alvo específico de Bianchi é a coletânea editada por Ateljevic, Pritchard e Morgan (2007), mas muitos dos seus argumentos são aplicáveis ao manual da Sage, que, na conclusão, subscreve a vertente mais crítica dos estudos de turismo (Jamal e Robinson 2009: 699). Alguns dos autores da Sage contribuíram também para esta coletânea (por exemplo, Tazim Jamal, Adrian Franklin, Cara Aitchinson e Keith Hollinshead). 
sua máxima expressão no materialismo cultural de Raymond Williams, com origem no diálogo tenso entre a tradição idealista alemã e a tradição de crítica cultural marxista (Williams 1995 [1981]; Mulhern 2000). A partir da década de 1990, quando os estudos culturais se demarcaram definitivamente da tradição marxista, o culturalismo "qualificado" de Williams foi sendo substituído por um culturalismo mais intenso e, de certa forma, "desmaterializado". Esta "desmaterialização" dos estudos culturais é percetível em vários artigos do manual da Sage, mas é também motivo de algum desconforto, como transparece no capítulo sobre turismo e estudos de género, que advoga a sua "rematerialização" (Jamal e Robinson 2009: 638). ${ }^{9}$ Nos capítulos dedicados à indústria de turismo global (capítulo 32) e às políticas internacionais (capítulo 33), também se aponta a necessidade de se efetuarem mais estudos sobre o lado da oferta (2009: 582) e de se recuperar a relação entre consumo e produção (2009: 583, 590), e, na conclusão, os organizadores referem a importância (e escassez) de trabalhos empíricos sobre organizações e empresas ligadas ao turismo (2009: 696).

No final, questões teóricas à parte, impõe-se-nos a pergunta: como estudar o turismo hoje? O que nos fica destas duas obras é a importância dos estudos locais. O turismo tende a fomentar grandes discussões especulativas - desde polémicas de cariz político (que o veem ou como libertador dos povos e promotor da harmonia universal, ou, no extremo oposto, como destruidor de culturas e criador de desigualdades) até considerações de ordem filosófica ou estética (que tomam o turismo e o turista como metáforas de uma condição humana universalizante). Num e noutro caso é reciclada toda uma retórica que, sob diversas formas (discursos oficiais de promoção turística, publicidade, literatura, cinema), irriga o quotidiano e a própria academia.

Ultrapassar esta retórica - ou, pelo menos, reconhecer a sua força e os seus limites - constitui um dos maiores desafios neste campo. Ao dar voz aos turistas - tradicionalmente denegridos (Culler 1988) ou ausentes da maior parte dos estudos - através da etnografia, a antropologia tem desempenhado um papel particularmente importante a este nível. Como Leite e Graburn sublinham no capítulo da Sage, a extrema mobilidade dos turistas torna-os de difícil estudo (Jamal e Robinson 2009: 36-37), requerendo soluções metodológicas inovadoras, capazes de combinar, por exemplo, a observação participante (de longa,

9 Uma das vantagens do manual da Sage acaba por ser a justaposição de contributos das ciências sociais e das áreas aplicadas, o que nos permite analisar os excessos de uns e de outros. Se, por exemplo, os primeiros tendem a relativizar o turismo, a ponto de colocar o termo "indústria" entre aspas (por exemplo, Jamal e Robinson 2009: 537), os segundos oferecem definições concretas de indústria de turismo, agora sem aspas (por exemplo, 2009: 559-560). Do mesmo modo, enquanto a maior parte dos autores das ciências sociais mostram relutância em falar do turismo como consumo, os contributos de dentro da indústria não se coíbem de falar em "produtos turísticos", sem por isso omitirem o seu caráter "intangível" e "orientado para a experiência" (2009: 564). 
média e curta duração) com inquéritos, entrevistas (muitas vezes recorrendo a estímulos visuais, tais como fotografias e vídeos domésticos, ou a objetos), diários de viagem e, mais recentemente, blogues e redes sociais. Esta "recuperação" do turista tem-se feito sentir, com efeitos positivos, também noutras áreas: a recuperação das práticas turísticas na história do turismo tem permitido contrariar as abordagens dominantes, que sobrevalorizavam os discursos normalizadores da atividade turística e privilegiavam uma historiografia feita de cima para baixo (Vidal 2010).

No entanto, alguns excessos têm também acompanhado esta reorientação para os turistas, designadamente quando estes ameaçam tornar-se os "atores principais do turismo" num quadro de "exoticização da mobilidade" que, para além de introduzir desequilíbrios no campo das observações, nos diz mais sobre as posições cosmopolitas dos investigadores do que propriamente sobre o objeto das suas investigações (Silva 2004: 9). Na conclusão ao volume da Sage, os organizadores Tazim Jamal e Mike Robinson (2009: 696) reconhecem como dominante a tendência para privilegiar os locais de destino e o capítulo de Mavrič e Urry é exemplificativo da aposta teórica e metodológica na mobilidade. A proposta de Maria Cardeira da Silva de encarar o turismo como um "novo terreno da antropologia" promete colmatar alguns destes excessos. A ideia é tomar o ponto de vista dos lugares (turísticos, de origem e de destino) para produzir "observações diretas e descrições densas" (Silva 2004: 10), desse modo explorando a capacidade da antropologia de "atribuição de voz ao local", sem descurar um "enquadramento mais vasto no seu quadro de produção social" (Silva 2004: 11 ). Esta perspetiva é muito diferente da onda de estudos que se têm debruçado sobre os processos de tipificação (branding) dos lugares, em que o ponto de chegada é, muitas vezes, a negação do lugar, isto é, a reconceptualização dos lugares turísticos como "não-lugares" (cf. Jamal e Robinson 2009: 47). Recusando a reificação da cultura (mas admitindo a banalidade deste processo), Cardeira da Silva sublinha que não se trata de regressar a noções clássicas do "local", mas de reconhecer as vantagens deste ponto de vista.

Com efeito, é ao nível do "local" que encontramos as marcas das mobilidades que, apesar de transitórias, não deixam de largar lastro, desse modo tornando visível a vasta dinâmica dos lugares turísticos - "espaços agenciados por práticas", que são o produto de "um jogo complexo entre os discursos, os interesses e os usos" (Vidal 2010: 11 1). A questão da visibilidade e da invisibilidade é aqui crucial: mais do que deter-nos na constatação (ou rejeição) da primazia da visão no turismo, é importante identificar aquilo que, em contextos turísticos locais, é visível e invisível, e refletir sobre esta relação. A clássica distinção entre backstage e front stage (MacCannell 1999 [1976]) apontava já para a importância deste aspeto no turismo; no entanto, é possível ir mais longe, para lá da questão da autenticidade (que motivou a discussão de MacCannell), 
a fim de recuperar um sentido de visão (e atenção) que seja capaz de nos voltar a conectar com a materialidade das coisas e, através dela, com os processos sociais e culturais (muitas vezes invisíveis) que estão na base daquilo a que convencionalmente chamamos "turismo".

Por outras palavras, para além do regresso a perspetivas "locais", uma rematerialização dos estudos de turismo implicará também uma revalorização da visualidade, num quadro conceptual que rejeita a redução do olhar a um instrumento de controlo e disciplina (a tendência, de inspiração foucaultiana, ainda dominante); que se afasta do conceito de tourist gaze (Urry 2002), que tem monopolizado grande parte das discussões sobre visão e turismo (sobretudo de inspiração anglófona, mas não só); e que, reconhecendo os limites e as limitações do olhar "científico", não deixa de atribuir uma componente epistemológica e de crítica social (pelo menos potencial) ao ato de ver e/ou "tornar visível". Dois exemplos diferentes de estudos que se poderiam inserir nesta linha são Swords e Mize (2008), que criticam os conceitos de tourist gaze e performance para abordar as questões da terra e do trabalho em contextos turísticos mexicanos e porto-riquenhos, e Löfgren, que lamenta o facto de os estudos sobre turismo se terem vindo a focar demasiado "on the dramatic and eventful, the visible and explicit" (2008: 86), em detrimento das experiências dos turistas consideradas desagradáveis ou simplesmente banais.

A ausência do trabalho e do banal - consequência de uma conceção de turismo como espaço de lazer e do fora do comum, que a indústria não deixa de incentivar - constitui, de resto, um dos maiores equívocos dos estudos de turismo, que um enfoque excessivo no turismo como espaço de produção de identidades e culturas (ou até de "signos") tende a perpetuar. ${ }^{10}$ Os métodos visuais (que recebem pouca atenção no volume da Sage) ${ }^{11}$ poderão ajudar a colmatar este tipo de lacuna, ao permitirem estabelecer conexões e tornar presente o ausente, preconizando uma nova forma de conceber a visualidade nos estudos de turismo (cf. Crang 2009). Reconhecer, a partir de observações diretas e recebidas, que há um rol de coisas, processos e relações que, não sendo imediatamente visíveis, todavia fazem "parte da fotografia", constitui um passo importante na rematerialização e necessária revitalização dos estudos de turismo.

10 Este é um dos riscos das recentes teorias sobre turismo "virtual", associado ao cinema, à televisão e à Internet, que elogiam as novas práticas (supostamente mais "limpas" e sustentáveis por não implicarem o uso de transportes ou o consumo de água nos locais), fazendo vista grossa aos processos de exploração de recursos naturais e humanos que continuam a ser mobilizados (por exemplo, nas áreas da energia e da mineração de metais raros).

1 Exceções são o capítulo 3, de Leite e Graburn, e o capítulo 36, de Mavrič e Urry. 


\section{BIBLIOGRAFIA}

ATElJEVIC, Irena, Annette PRITCHARD, e Nigel MORGAN (orgs.), 2007, The Critical Turn in Tourism Studies: Innovative Research Methods. Amesterdão, Elsevier.

BELL, Claudia, e John LYALL, 2008 [2002], “The accelerated sublime: thrill-seeking adventure heroes in the commodified landscape”, em Simon Coleman e Mike Crang (orgs.), Tourism: Between Place and Performance. Oxford e Nova Iorque, Berghahn, 21-37.

BIANCHI, Raoul V., 2009, “The 'critical turn' in tourism studies: a radical critique”, Tourism Geographies, 11 (4): 484-504.

CRANG, Mike, 2009, "Visual methods and methodologies", em Dydia DeLyser et al. (orgs.) The Sage Handbook of Qualitative Geography. Londres e Thousand Oaks, Sage, 208-225.

CULLER, Jonathan, 1988, “The semiotics of tourism”, em Jonathan Culler, Framing the Sign: Criticism and Its Institutions. Norman, University of Oklahoma Press, 153-167.

DANN, Graham M.S., e Giuli Liebman PARRINELlO (orgs.), 2009, The Sociology of Tourism: European Origins and Developments. Bingley, UK, Emerald, Tourism Social Science Series, 12.

FRANKLIN, Adrian, e Mike CRANG, 2001, "The trouble with tourism and travel theory?", Tourist Studies, 1 (1): 5-22.

GALANI-MOUTAFI, Vasiliki, 2000, "The self and the other: traveler, ethnographer, tourist", Annals of Tourism Research, 27 (1): 203-224.

JAMAL, Tazim, e Mike ROBINSON (orgs.), 2009, The Sage Handbook of Tourism Studies, Los Angeles e Londres, Sage.

LÖFGREN, Orvar, 2008, "The secret lives of tourists: delays, disappointments and daydreams", Scandinavian Journal of Hospitality and Tourism, 8 (1): 85-101.

MacCANNELL, Dean, 1999 [1976], The Tourist: A New Theory of the Leisure Class. Berkeley e Los Angeles, University of California Press.

MULHERN, Francis, 2000, Culture/Metaculture. Londres e Nova Iorque, Routledge.

ROJEK, Chris, 2007, Cultural Studies. Cambridge, Polity.

ROJEK, Chris, e John URRY (orgs.), 1997, Touring Cultures: Transformations of Travel and Theory. Londres e Nova Iorque, Routledge.

SILVA, Maria Cardeira da, 2004, "Introdução: por uma antropologia dos lugares turísticos", em Maria Cardeira da Silva (org.), Outros Trópicos: Novos Destinos Turísticos, Novos Terrenos da Antropologia. Lisboa, Livros Horizonte, 7-18.

SMITH, Valene L. (org.), 1978, Hosts and Guests: The Anthropology of Tourism. Oxford, Basil Blackwell.

SWORDS, Alicia, e Ronald L. MIZE, 2008, "Beyond tourist gazes and performances: U.S. consumption of land and labor in Puerto Rican and Mexican destinations", Latin American Perspectives, 35 (3): 53-69.

URRY, John, 2002, The Tourist Gaze. Londres, Sage (2. ${ }^{\text {a }}$ edição).

VEIJOLA, Soile, e Eeva JOKINEN, 1994, "The body in tourism”, Theory Culture \& Society, 11 (3): 125-151.

VIDAL, Frédéric, 2010, "Faire la ville et pratiquer des lieux: l'histoire du tourisme sur les pas de Michel de Certeau”, Revue d'Histoire des Sciences Humaines, 23: 99-1 15.

WILliamS, Raymond, 1995 [1981], The Sociology of Culture. Chicago, The University of Chicago Press. 